\title{
Effects of temperature and concentration on mechanism and kinetics of thermally induced deposition from coffee extracts
}

\author{
Marek Kroslak ${ }^{1,3}$, Massimo Morbidelli ${ }^{1}$, Jan Sefcik ${ }^{2 *}$ \\ ${ }^{1}$ Institut für Chemie- und Bioinginieurwissenschaften, ETH Zurich, Zurich, Switzerland \\ ${ }^{2}$ Department of Chemical and Process Engineering, University of Strathclyde, Glasgow, UK \\ ${ }^{3}$ Present address: SEP Salt \& Evaporation Plants Ltd., Winterthur, Switzerland
}

Corresponding author: Jan Sefcik, E-mail: jan.sefcik@strath.ac.uk, Address: University of Strathclyde, 75 Montrose Street, Glasgow, G1 1XJ, UK

1 Production of soluble (instant) coffee powders typically involves extraction of roasted coffee by water followed by evaporation in order to concentrate extracts before spray or freeze drying to produce dry coffee powder. In the course of evaporation, deposition of dissolved material from

4 coffee extracts is a major cause of fouling at heat exchange surfaces of evaporators. Therefore in order to improve design and optimization of evaporation processes of coffee extracts, a better understanding of deposition mechanism and kinetics is needed. We used Optical Waveguide Lightmode Spectroscopy (OWLS) to monitor the initial formation of nanometer scale deposits on surfaces exposed to coffee extracts. OWLS measurements were complemented by light scattering from extract solutions, gravimetry of macroscopic deposits and scanning electron microscopy imaging of deposited layers. Primary molecular-scale layers of about $1 \mathrm{mg} / \mathrm{m}^{2}$ were rapidly

11 formed in the first stage of deposition even at ambient temperature, followed by the secondary 12 deposition with kinetics strongly dependent on temperature. Secondary deposition rates were low 13 and largely independent of the extract concentration at ambient temperature, but became strongly 14 dependent on extract concentration at elevated temperatures. In particular, activation energies for 15 deposition between 25 and $70^{\circ} \mathrm{C}$ were much higher for the original extract $(13.3 \% \mathrm{w} / \mathrm{w}$ solids) than for diluted extracts (up to $1.3 \% \mathrm{w} / \mathrm{w}$ solids). Furthermore, heating of the original extracts above $60^{\circ} \mathrm{C}$ resulted in rapid aggregation of suspended macromolecules into large clusters, while only gradual aggregation was observed in diluted extracts. 
Keywords: coffee extracts; deposition; aggregation; fouling; evaporation; heat exchange

\section{Introduction}

Deposition and fouling play an important role in various industrial and biomedical applications, such as filtration, heat exchange, evaporation, deposition in blood vessels, implant biocompatibility and others. There are instances where deposition is desired, as long as it can be controlled, but others where it is not. Typical examples are in food processing industries, where various liquids (solutions or dispersion) are treated in falling film evaporators in order to produce more concentrated solutions. Extensive fouling of evaporator surfaces can occur over a period of hours to days, depending on properties of a particular system. Fouling leads to build-up of a thick layer deposited on the evaporator surface, which causes a gradual decrease in the efficiency of the heat transfer and the eventual interruption of the production process in order to proceed to surface cleaning.

Various characterization methods have been used to study fouling kinetics. Macroscopic deposits can be conveniently studied using gravimetry, which has the advantage of relative simplicity and direct data interpretation. Quartz crystal microbalance has been used to study protein adsorption and it provides useful quantitative information related to mass and viscoelastic properties of deposited material (Höök et al., 2002). Another useful technique widely used in fouling studies is optical microscopy, providing visual characterization of deposited layers down to the micrometer scale. Scanning electron microscopy or atomic force microscopy can provide details in the nanometer range, but they typically require sample manipulations, which may lead to significant changes with respect to its original morphology. This especially concerns biological systems, which are often sensitive to changes in the environment.

On the other hand, spectroscopic characterization methods can provide molecular level insight into the mechanisms governing the deposition process, especially at its early stages. Surface spectroscopic techniques, such as Optical Waveguide Lightmode Spectroscopy (OWLS), have the advantage of non-destructive, in situ monitoring of solid-liquid interfaces and provide a useful tool to study adsorption and deposition at solid-liquid interfaces. A limitation of this and similar reflectance-based techniques (e.g., ellipsometry, reflectometry) is that there is a limited extent of the deposit thickness that can be measured, typically not exceeding few tens of nanometers. 
52 since this waveguide-based method does not require the reflecting laser beam to pass through the 53 suspension.

54 The extracts obtained from ground roasted coffee beans are darkly colored mixtures containing 55 proteins, polysaccharides and organic acids in both soluble and insoluble (colloidal) form 56 suspended in an aqueous matrix. We note that there is a significant amount of lipids in (roasted) 57 coffee beans, but lipids are poorly soluble in water and their concentration in coffee extracts is 58 therefore very low. We are not aware of any previous studies on deposition from coffee extracts 59 or similar systems. Most of previous studies about surface fouling refer to the deposition of 60 proteins, mostly of animal origin. When protein solutions come into contact with an interface a 61 spontaneous deposition is typically observed. Published studies have been mostly focused on 62 protein-surface interactions, mainly at ambient temperature. Protein deposition is affected by $\mathrm{pH}$, 63 electrolyte concentration and temperature, which may specifically affect the protein functional 64 groups or change its geometrical arrangement. Polysaccharides, which represent a significant component of the coffee extracts, tend to copolymerize with proteins at elevated temperatures 66 (Maillard reaction), and the resulting copolymers are also expected to be subject to fouling.

Considering interphase interactions of deposited entities with solid surfaces, we can divide the deposition processes into two main groups:

i) The first group involves monolayer systems, where the main driving force for the deposition is due to the interaction potential difference between a bulk solution and a solid surface. Electrostatic double layer repulsion prevents charged polymer colloids from aggregating to each other, resulting in a stable deposited monolayer on the solid surface, which is made resistant against further deposition by the same electrostatic repulsive forces which keep suspended colloids stable in the bulk solution.

ii) The second group involves multilayer systems, where the repulsive interactions between the primary deposited layer and the bulk solution entities are reduced, so that subsequent deposition on the top of the primary layer can proceed. Multilayer growth can be achieved by altering the bulk solution composition, mainly through changes of $\mathrm{pH}$ and/or electrolyte concentration or, as in the system studied here, by increasing the temperature. Typically, fouling phenomena occur

80 through the multilayer deposition. In this case the deposition is driven by interactions of 81 previously deposited entities with those in the bulk, similar to aggregation in the bulk solution 82 itself, so that fouling becomes independent from surface properties of the original substrate after 83 the first few layers are deposited. 
Multilayer film deposition at ambient temperature was studied by Picart et al. and Lavalle et al. (Picart et al., 2001; Lavalle et al., 2004), where well defined polyelectrolyte multilayers and multilayer polyelectrolyte/protein films were investigated by OWLS and scanning angle reflectometry. It was shown that OWLS was able to monitor the deposition process from the initial deposited layer up to a thickness of more than $40 \mathrm{~nm}$, while reflectometry could be used only after a few nanometers have been deposited up to about the same maximum thickness. This study of polyelectrolyte multilayer growth pointed out the important role of solution $\mathrm{pH}$ and charge distribution inside the film on the layer buildup mechanism.

Studies of Griesser et al. (Griesser et al., 2002) on the deposition of complex protein mixtures (differing in the isoelectric point) for different bulk solution electrolyte concentrations on variously grafted polysaccharide layers and polymer coatings showed that coatings with substantial surface charge can be resistant to protein adsorption of the same charge, although they cannot be considered as a universal protein-resistant surface for all protein mixtures. been rarely investigated. As reported in the review by Nakanishi et al. (Nakanishi et al., 2001), this may be in part related to the associated experimental difficulties. The most commonly temperature driven fouling system studied in the literature is milk (Changani et al., 1997; Jong, 1997; Visser \& Jeurnink, 1997; Anema, 2000). This is a complex mixture of proteins, fats, carbohydrates, minerals and enzymes. There are two major components playing a role in milk

103 fouling. Deposits formed between $60^{\circ} \mathrm{C}$ and $100^{\circ} \mathrm{C}$ are predominantly proteinaceous (with $\beta$ 104 lactoglobulin as the dominant protein), while deposits formed above $100^{\circ} \mathrm{C}$ are rich in minerals.

105 Thermal properties and aggregation and deposition behavior of proteins are in general strongly 106 dependent on $\mathrm{pH}$ and on the presence of other components, such as calcium ions, lactose or 107 casein. Upon heating at neutral $\mathrm{pH}$, the proteins initially unfold and expose their inner 108 hydrophobic cores and free thiol groups, which initiates their spontaneous aggregation and can 109 also lead to their deposition on surfaces (Kroslak et al., 2007; Vogtt et al., 2011; Grancic et al., 110 2012). At ambient temperature $\beta$-lactoglobulin forms monolayer due to its interaction with the 111 bare surface, which is the typical behavior observed for various proteins (Relkin, 1996; Van 112 Tassel, 2003; Voros, 2004; Sava et al., 2005).

113 The main scope of this work was to investigate the mechanism and kinetics of surface 114 deposition from coffee extract induced by an increased temperature. Using the temperature 115 control setup developed for the OWLS instrument allowed us to obtain unique insights into the 
116 deposition process in these systems. A better qualitative and quantitative understanding of the

117 deposition process should provide a rational basis for possible process modifications leading to

118 decreased fouling, thus improving the heat transfer in evaporators used for the production of 119 concentrated extracts.

120 In the following we investigate the primary layer formation on several different surfaces at 121 ambient temperature and at various $\mathrm{pH}$ and electrolyte concentrations. Next, we investigate the

122 secondary deposition driven by temperature on the primary layers previously deposited on a silica

123 surface. The structure of deposited layers is also analyzed using scanning electron microscopy 124 while the macroscopic deposition kinetics at longer times is measured by gravimetry. Light 125 scattering is used to monitor the corresponding aggregation processes in the bulk suspension for 126 variously diluted extracts at elevated temperatures.

\section{Optical Waveguide Lightmode Spectroscopy}

130 Optical waveguide lightmode spectroscopy is based on measurements of changes of the 131 effective refractive index of an optical waveguide when a thin film forms at the waveguide 132 surface. The presence of the thin film changes the evanescent electromagnetic field in a close 133 vicinity of the waveguide surface and it influences the light reflection from the waveguide 134 surface. This results in a shift of the incidence angle of a light beam leading to a lightmode 135 guided along the waveguide. By measuring the incidence angle $\alpha$ corresponding to the resonance 136 maximum of the light incoupled in the waveguide it is possible to determine an effective 137 refractive index $N$ of the light propagating along the waveguide and from that the thin film 138 (deposited) mass per surface area (please see further details in Supplementary Information).

\section{Experimental}

\section{$141 \quad$ Materials}

142 The dry solid content of the coffee extract (provided by Nestlé Product Technology Centre 143 Orbe, Switzerland) considered in this work is $13.3 \mathrm{wt} \%$ and the $\mathrm{pH}$ is 5.0 . The dry mass of the 144 suspension is constituted of $7.4 \%$ proteins, $35 \%$ carbohydrates, $3.2 \%$ minerals and $54.4 \%$ other 145 organic molecules like melanoidines, organic acids and ash. At the natural $\mathrm{pH}$ of the coffee 146 extract ( $\mathrm{pH} 5)$ most of the proteins are negatively charged (36\%), 1.2\% are positively charged, $14730 \%$ are polar uncharged (mainly aliphatic), $23 \%$ are aromatic and the rest is not determined. The 
sediments constitute $2 \%$ of the overall dry content. All solutions were prepared with ultra pure water (Millipore, $18 \mathrm{M} \Omega$ ) degassed under vacuum before use in order to reduce bubble formation in the spectroscopy cell.

151 Silica-Titania planar waveguides (OW 2400) were purchased from Microvacuum Ltd. 152 (Budapest, Hungary). They consist of a 1-mm-thick AF45 glass substrate and a 180-nm thick $153 \mathrm{Si}_{0.75} \mathrm{Ti}_{0.25} \mathrm{O}_{2}$ waveguiding surface layer, with dimensions of $1.2 \times 0.8 \times 0.1 \mathrm{~cm}$. The isoelectric point 154 (IEP) of silica is 3.0 and of titania around 5.5 (Kosmulski, 2001). The waveguide layer has an approximate thickness of $t_{F} \sim 180 \mathrm{~nm}$ and a refractive index of $n_{F} \sim 1.76$. Five different surfaces have been used in this study to investigate the ambient temperature deposition process. These include the negatively charged silica and niobia surfaces, the positively charged alumina surface, and the hydrophobic polystyrene (PS) and poly(ethylene glycol)-3.5-poly(L-lysine) (PEG-3.5PLL) surfaces. At elevated temperature only the silica modified surface has been used.

All the surfaces mentioned above have been obtained through a suitable coating procedure, covering the original waveguide film with layers 10-15 $\mathrm{nm}$ thick. The silica and alumina coated waveguides were purchased from Microvacuum Ltd. (Budapest, Hungary). The IEP of alumina is 8 (Kosmulski, 2001). The niobia coated waveguides were sputter coated on the original waveguide, using reactive magnetron sputtering (PSI, Villigen, Switzerland). The IEP of niobia is 4.3. Before each deposition experiment, all oxide surfaces were activated in $\mathrm{NaOH}$ solution at $\mathrm{pH}$ 11 for 3 hours. Afterwards, the waveguides were rinsed with Millipore water and dried with nitrogen. This procedure activates the hydroxyl groups on the accessible surface.

A polystyrene (PS) layer approximately $15 \mathrm{~nm}$ thick was coated on the silanized original waveguide using 1\% polystyrene dissolved in toluene at rotation speed $3000 \mathrm{rpm}$ for 1 minute (Extrand, 1994; Schubert, 1997). PS used in this study was PS Standard 30'000 from SigmaAldrich (Product Number 81408) with $M_{p}=32500, M_{n}=31000, M_{w}=32000, M_{w} / M_{n}=1.02$. Silanization by hexamethyldisilazane, from Fluka, (Lot. No. 427155/1 44601) was used to make the originally hydrophilic oxide surface hydrophobic (Huang, 2002). PEG-3.5-(PLL), a polycationic co-polymer (grafting ratio of 3.5; Huang, 2002), positively charged at neutral pH (Huang, 2002), was spontaneously adsorbed on the negatively charged original surface from aqueous solution. PEG-3.5-(PLL) modified waveguides were obtained from the Laboratory of

178 Prior to the SLS measurements the coffee extract was filtered with a $0.8 \mu \mathrm{m}$ filter (Millipore) in 179 order to remove bigger aggregates from the coffee extract. This does not change significantly the 
180 overall dried mass of the filtrate compared to the original extract. The removal of these particles

181 is needed to reduce skewing of the measurements caused by big aggregates.

182 OWLS

183 Deposition experiments were performed in OWLS apparatus type OWLS 110 made by Micro 184 Vacuum Ltd, Budapest, Hungary with an integrated temperature control unit. The waveguide is 185 placed in a measuring cell, which is a channel $8 \mathrm{~mm}$ long with rectangular cross section $(0.8 \mathrm{~mm}$ 186 high and $2 \mathrm{~mm}$ wide) with a volume of $12.8 \mu \mathrm{l}$, with entrance and exit ports to allow for 187 continuous flow through. All delivery tubes and the measuring cell are made of PTFE. The flow 188 through operation mode has been selected in order to guarantee exposure to a fresh extract with 189 constant composition over time. The waveguide parameters $n_{f}$ and $t_{f}$ are measured through a 190 preliminary set of experiments where water is flushed through the deposition cell at ambient 191 temperature.

192 In the deposition experiments at ambient temperature the waveguide surface was exposed to the

193 coffee extract for at least one hour leading to completion of the primary deposited layer on the 194 bare surface. The flow rate is held constant at $1 \mathrm{ml} \cdot \mathrm{min}^{-1}$ by the programmable syringe pump Vit195 Fit (Lambda, Czech Republic). After deposition, the sample is washed with water for at least 1 196 hour at ambient temperature. This was found sufficient to wash out all the electrolytes adsorbed 197 on the deposition process.For the runs at higher temperatures, a specific experimental procedure 198 has been developed which is described in detail in Supplementary Information. After each 199 deposition experiment the waveguide was cleaned by a short exposure to a strong oxidizing agent 200 (3 seconds in chromic acid), followed by water rinsing. After the cleaning procedure, the position 201 of the resonance spectra was checked and compared with the initially measured one to check that 202 no waveguide damage occurred during cleaning.

\section{Gravimetry}

204 Gravimetry measurements were used as complementary experiments for OWLS measurements.

205 While the OWLS was used in this work to track deposition for surface coverages up to $30 \mathrm{mg} \cdot \mathrm{m}^{-}$ $206^{2}$, in order to study the deposition at longer times, when thicker deposits are obtained, we used 207 gravimetry, the lower detection limit of which for the given experimental system is about 50 $208 \mathrm{mg} \cdot \mathrm{m}^{-2}$. Gravimetry is probably the most conventional method to study macroscopic deposition. 209 It is based on weighing the difference between adsorbent weight before and after the adsorption 210 process, and therefore its sensitivity is limited by the accuracy of the weighting procedure. The 211 silica plate was placed into a gravimetry cell, constituted by a channel $180 \mathrm{~mm}$ long, with 
212 rectangular cross-section $0.5 \mathrm{~mm}$ high and $18 \mathrm{~mm}$ wide. All delivery tubes were made of 213 stainless steel and the gravimetry cell was made of alumina. The channel geometry has been 214 selected so that we can use the hydrodynamic model for laminar flow between two infinite 215 parallel plates to calculate the hydrodynamic regime inside the channel. Using this model we can 216 determine the flow rate to be fed to the channel so that the velocity gradient at the surface of the 217 waveguide is equal to that in the OWLS cell. The calculated velocity gradient in the OWLS cell

218 is about $500 \mathrm{~s}^{-1}$, which corresponds to a volume flow rate in the channel of $32 \mathrm{ml}^{-\mathrm{min}^{-1}}$. A 219 peristaltic pump was used to deliver the extract preheated to the desired temperature shortly 220 before entering the measurement cell. The entire gravimetry cell was held at constant 221 temperature. Washing with pure water was performed for one hour after the cooling step as in the 222 OWLS experiments.

\section{Light scattering}

224 Light scattering experiments were performed on coffee extract in order to compare the aggregation in the liquid bulk with the surface deposition. All measurements have been taken with a small angle light scattering instrument (Mastersizer 2000 by Malvern) after preliminary filtration with $0.8 \mu \mathrm{m}$ filter. The original extract was heated and kept for one hour at constant temperature in the range $25-80^{\circ} \mathrm{C}$ so as to undergo Brownian aggregation. Samples were withdrawn at fixed times and quickly diluted 200 times with pure water in order to stop aggregation and avoid multiple scattering in the light scattering measurements. Alternatively, the extract was immediately diluted and then heated at the desired temperature so as to monitor directly in-situ the aggregation process by light scattering without any sampling procedure.

\section{Results and discussion}

\section{Estimation of OWLS parameters}

237 In order to evaluate the deposited mass from the measured $N(T E)$ we need to supply optical parameters which correspond to the conditions inside the deposition cell. The refractive indices

$239 n_{S}$ and $n_{C}$, for the waveguide support and the cover liquid, respectively have been taken from the

240 literature or measured independently at various temperatures and are summarized in Table $\mathbf{1}$. The 241 waveguide thickness $t_{F}$ and refractive index $n_{F}$ may vary slightly depending on the measurement conditions and therefore have been evaluated before each experiment. 
Let us now consider the evolution of the derivative of the dielectric constant with respect to the mass concentration of deposit $d c / d \varepsilon$ (see Supplementary Information for further details). For 245 this the refractive indices of variously diluted coffee extracts were measured by refractometer at 246 wavelength $632.8 \mathrm{~nm}$ for four different temperatures $\left(20,25,40,60^{\circ} \mathrm{C}\right)$. The measured values are 247 provided in Table 1 where $x_{E}$ represents the weight concentration of solid content in coffee 248 extract suspension. Since the relative dielectric constant can be computed from the refractive 249 indices in the table as $\varepsilon=n_{C}^{2}$, the derivative $d c / d \varepsilon$ (where $c=x_{E}$ ) can be readily obtained. This 250 procedure has been repeated at the four considered temperatures and obtained values are fitted by 251 following expression, where $\mathrm{T}$ is given in ${ }^{\circ} \mathrm{C}$ :

$$
\left(\frac{d c}{d \varepsilon}\right)_{T}=-3.47 \cdot 10^{-6} T^{2}+4.028 \cdot 10^{-3} T+1.642 \quad\left[\mathrm{~g} / \mathrm{cm}^{3}\right]
$$

As can be seen for this particular case, the term $d c / d \varepsilon$ changes just very little within measured temperature range $20-60^{\circ} \mathrm{C}$ (i.e. a temperature change of $40^{\circ} \mathrm{C}$ leads to an increase of $3 \%$ ). Here we can notice that the value determined experimentally at ambient temperature for the coffee extract $\left(1.74 \mathrm{~g} . \mathrm{cm}^{-3}\right)$ is similar to the value conventionally used to determine the deposited mass from various biomolecular systems ( 1.89 g.cm $\left.{ }^{-3}\right)$ (Defeijter, Benjamins \& Veer, 1978).

\section{Deposition at ambient temperature}

A typical result of the OWLS measurement is shown in Figure 1 in terms of mass deposited during a primary exposure of two waveguides, the silica and the polystyrene coated ones, to the coffee extract (solid concentration $13.3 \mathrm{wt} \%$ ). After equilibration with pure water the extract was pumped at constant flow rate through the measuring cell, and at the end of the deposition process the flow was switched back to pure water and the washing process started. These two times are indicated by arrows in the figure. Typical deposition coverage was about $1 \mathrm{mg} \cdot \mathrm{m}^{-2}$ after washing with pure water for one hour at ambient temperature.

266 It can be seen that in the case of the hydrophobic polystyrene coated waveguide the deposited mass increased almost instantaneously to about $2 \mathrm{mg} \cdot \mathrm{m}^{-2}$, and then under very slow growth, which in the following we refer to as the secondary growth. During washing there was a rapid decrease of the deposited mass to about $1 \mathrm{mg} \cdot \mathrm{m}^{-2}$, followed by a period of time where the mass decrease was so slow that we can consider the deposit as stable in time. When the silica surface was exposed to the extract, the deposited mass was growing rapidly for a longer time, i.e. about

272 half an hour, followed again by a steady but very slow increase corresponding to the so-called secondary growth. Also in this case washing starts very fast and then slows down considerably, 
274 leading to a stable deposit. The mass measured at this point represents the amount of material 275 irreversibly deposited on the surface, since the waveguide is at the same conditions as at the 276 beginning of the experiment (in contact with pure water at ambient temperature). And this will be referred to in the following as irreversible primary layer.

278 It is worth noting that while the response of the neutral polystyrene surface is almost instantaneous, the one of the charged silica surface is slower and more pronounced. This is due to the fact that in the second case not only the extract material, but also all the various electrolytes present in the solution are adsorbed or deposited on the surface. These species are however removed during washing, so that it can be observed that the irreversibly deposited amount is very close to that obtained for polystyrene. This can be confirmed by the data reported by Nellen et al. (Nellen et al., 1992) for simple electrolyte solutions, which indicate typical saturation times of about $40 \mathrm{~min}$.

The sensitivity of the silica waveguide to electrolytes is well known and the usual way to eliminate it is to use a background medium with the same electrolyte composition as the covering liquid under examination. Since the coffee extract used here was a complex buffering mixture, it was not possible to prepare a matching background medium. Therefore, in addition to the deposition of the extract components, we need to take into account the partitioning equilibrium between the solution and the solid surface. The closer the solution $\mathrm{pH}$ is to the isoelectric point of a given surface, the less significant the adsorption of electrolytes is (Sefcik et al., 2002). When the silica surface is exposed to an electrolyte solution at $\mathrm{pH}=3$, which corresponds to its isoelectric point, there is no charging response from the waveguide surface, similarly to the case of neutral polystyrene surface.

In Figure 2 we show the results of deposition measurements for multiple subsequent exposures of a silica coated waveguide to the coffee extract. The first exposure leads to the formation of an irreversible primary layer of about $1.2 \mathrm{mg}^{-2} \mathrm{~m}^{-2}$ shown in Figure 1. The second and third exposures exhibit a very similar behavior. It is worth noticing that for all three subsequent exposures, although the secondary growth region was extended over different times, the final irreversible deposit was substantially the same. This indicates that the material deposited during secondary growth is weakly bounded to the surface and is easily removed by washing with water.

303 The values of the irreversibly deposited mass obtained after the primary exposure to the extract on various surfaces are summarized in Table 2. Note that the obtained values are in the same range as those observed for pure proteinaceous solutions deposited on silica surfaces (Nakanishi 
et al., 2001). Silica and niobia surfaces (isoelectric point at $\mathrm{pH} 3$ and 4, respectively) are negatively charged in contact with the extract at its native $\mathrm{pH} 5$ and exhibit the same thickness of the deposit. A comparable deposited mass was observed on polystyrene (neutral hydrophobic surface) after $15 \mathrm{~min}$ of exposure, thus confirming that the irreversible primary layer builds up almost completely after quite a short time. The amounts deposited on PEG-3.5-PLL (positively charged at pH 5 since it contains sterically isolated amine groups) and alumina surfaces (positively charged) were smaller than those in the previous cases. It is remarkable that the extract dilution does not lead to any substantial difference in the deposited amount of primary layer, as shown by data in Table 2 for silica coated waveguide.

These data confirm the result reported by Paschke et al. (Pasche et al., 2005) that the electrostatic potential of the waveguide surface has only a moderate influence on the secondary deposition and can be efficiently screened by the thin primary irreversible layer, whose properties govern the following deposition process. This can be justified by the fact that the extracts considered here contain a substantial amount of soluble ions so that the expected electrical double layer thickness is below $1 \mathrm{~nm}$. Therefore electrostatic surface effects act only over a very short range, which is moreover further screened by the irreversible primary layer.

\section{Deposition at elevated temperatures}

323 Prior to the deposition measurements, the temperature response of the bare waveguide in pure water was investigated. The waveguide thickness $t_{F}$ and refractive index $n_{F}$ were evaluated (see Supplementary Information) with the $n_{C}$ and $n_{S}$ values reported in Table 1. As shown in

Figure 3, an increase in the waveguide thickness and a decrease in refractive index were observed with increasing temperature. We note that the temperature response slightly varies between individual waveguides, although the general trend is always the same and relative changes in waveguide properties are very similar. As indicated by Saini et al. (Saini et al., 1994) the change in the waveguide thickness can be attributed to thermal dilatation of the waveguide material.

It is worth noting that in the temperature response experiments conducted in pure water, when the waveguide was cooled down to ambient temperature, the waveguide parameters were slightly different compared to those before heating. This may indicate a gradual hydrolysis and possibly dissolution of the silica coated waveguide, particularly at higher temperatures. Therefore we minimized the heat exposure of the waveguide in water to a minimum necessary time. On the other hand, changes of the waveguide optical parameters were not observed during the extract 
338 deposition runs. The thin layer deposited from the extract can effectively protect the waveguide

339 from hydrolysis and dissolution reactions in two ways. First, it can partially isolate the oxide

340 surface from contact with the solution and secondly it reduces the mass transfer from the oxide

341 surface to the bulk liquid. All the other parameters needed to estimate the deposited mass from

342 are reported in Table 1.

343 In Figure 4a and Figure 4b we show a typical deposition experiment for the coffee extract at $34460^{\circ} \mathrm{C}$. All deposition runs started from a waveguide which had already undergone a primary 345 deposition at ambient temperature, and therefore was covered by an irreversible primary layer.

346 Accordingly, we refer to these experiments as secondary deposition runs in the following

347 sections. The adopted experimental procedure is described in the experimental section and in the

348 case of the experiment in Figure 4 is reported in detail in Table S1. The last column in the table 349 refers to the temperature which is shown in Figure 4a.

350 In Figure $\mathbf{4 b}$ the deposited mass is given as a function of time for silica coated waveguide for 351 the different periods listed in Table S1. It is seen that as soon as the extract enters the measuring 352 cell (period C) the deposited mass increases abruptly while at later times it follows an almost 353 linear, relatively slow, increase which constitutes the secondary growth of the deposit. The first 354 jump in deposited mass is due to the adsorption of the small electrolytes on the primary 355 irreversible layer. This is a rather fast process and the deposition of large molecules in such a 356 small time is probably negligible for the secondary deposition runs. In order to determine the 357 deposited mass it is necessary to bring the surface of the waveguide after deposition at the desired 358 temperature back to its initial state, i.e. in the presence of pure water at $25^{\circ} \mathrm{C}$. The total 359 irreversibly deposited mass of the coffee extract is then computed as the difference between the 360 mass measured at ambient temperature in water before the deposition (point $\mathrm{M}_{1}$ ) and after water 361 washing for one hour (point $\mathrm{M}_{2}$ ). The corresponding average deposition rate is given as the 362 increment of deposited mass divided by the exposure time at the elevated temperature.

363 It is worth noting that the average deposition rate determined by this method agrees well with 364 the one obtained from the slope of the deposited mass curve as a function of time during period $\mathrm{C}$ 365 in shown in Figure 4b. This is further supported by data collected for a moderately diluted 366 extract over a range of temperatures shown in Figure 5. This confirms that the two ways of 367 measuring the deposition rate, referred to as online and off-line respectively, yield comparable 368 results. Therefore the thickness of the solid layer deposited on the waveguide after a certain 369 duration of the deposition process corresponds to the secondary deposition rate measured during 
370 period C. The electrolytes and other reversibly adsorbed species responsible for the sudden jump 371 in the adsorbed mass at the very beginning of period $\mathrm{C}$ are all removed during the washing period 372 E.

373 As can be seen from the semi logarithmic plot in Figure 6, the deposition rate of the original 374 extract (solid circles) gradually increases by over two orders of magnitude when the temperature 375 increases from $25^{\circ} \mathrm{C}$ to $65^{\circ} \mathrm{C}$, beyond which the deposition rate does not increase any further. The 376 apparent plateau in the deposition rate above $65^{\circ} \mathrm{C}$ was also confirmed by gravimetry measurements (see below) and it could be due to a diffusion limited regime for the transport from the bulk to the interface. Effect of extract composition on deposition kinetics

The assembly of molecules and particles among themselves as well as at interfaces is controlled by their mutual interactions. Repulsive interactions, typically electrostatic or steric, between depositing entities are required in order to prevent mutual aggregation as well as surface fouling. Electrostatic interactions between colloidal particles are modulated most readily by solution $\mathrm{pH}$ and electrolyte concentration. Coffee extracts considered here contain molecules and colloidal particles with dissociable groups which are negatively charged at the normal extract $\mathrm{pH}$ values $\sim 5$, as indicated by electrophoretic mobility measurements of diluted extracts (zeta potential -15 $\mathrm{mV})$.

In an attempt to control deposition kinetics through electrostatic interactions, we studied deposition by modifying $\mathrm{pH}$ to values 4.0 and 6.5 (from the natural $\mathrm{pH}$ of 5) at ambient temperature and at $65^{\circ} \mathrm{C}$. As expected, by increasing $\mathrm{pH}$ the negative charges on the colloids increase, thus leading to slower deposition. In particular, the data reported in Table 3 show that the increase of $\mathrm{pH}$ from 4 to 6.5 results in a decrease of the secondary deposition rate by a factor of 2 . An even more pronounced decrease was observed at $65^{\circ} \mathrm{C}$, with a reduction of the secondary deposition rate by a factor of 5 when increasing $\mathrm{pH}$ from 4 to 6.5 .

395 The measured secondary deposition rates as a function of temperature are shown in Figure 6 for extracts at various solid concentrations: the original extract at $13.3 \mathrm{wt} \%$ and those diluted with pure water to $1.3,0.28,0.14$ and $0.034 \mathrm{wt} \%$. We note that due to a strong buffering effect of the coffee extract, the $\mathrm{pH}$ values of the diluted extracts were close to that of the original extract $(\mathrm{pH}$ 5), with the highest value of $\mathrm{pH} 5.5$ for the most diluted extract $(0.034 \mathrm{wt} \%)$. From the data in the

400 figure we observe that the rate of secondary deposition at the ambient temperature is only little 401 sensitive to the extract concentration. Dilution of the original extract by a factor of up to 400 
402 results in not more than a two fold decrease in the deposition rate, which at ambient temperature 403 is only barely distinguishable from the experimental error. In particular, we see that the 404 deposition rate for diluted extracts (solid concentration below $1.3 \mathrm{wt} \%$ ) is largely independent of 405 the extract concentration. This could be explained by recalling that there is always a reversibly 406 deposited layer present at the surface in contact with the extract. Let us assume that this reversible 407 layer is dense enough at all concentrations considered here so as to effectively saturate the 408 underlying irreversibly bound layer. Then the rate of growth of the irreversible layer may be simply driven by incorporation of the loosely deposited material saturating the interface, and hence it would be essentially independent from the solution composition. However, this does not explain why the deposition rates at elevated temperatures from the original extract are much higher than from diluted ones.

413 In Figure 7 we show the Arrhenius plot for deposition rates, where the data for the original 414 (13.3 wt $\%)$ and the most diluted extract (0.036 wt \%) are compared. The activation energy for 415 deposition of the original extract was found to be about $130 \mathrm{~kJ} / \mathrm{mol}$, corresponding to an increase 416 of the deposition rate by more than two orders of magnitude between 25 and $65^{\circ} \mathrm{C}$. However, the 417 deposition rate for the diluted extract, increased by less than 10 fold between 25 and $70^{\circ} \mathrm{C}$ 418 corresponding to an activation energy of about $30 \mathrm{~kJ} / \mathrm{mol}$. The difference in activation energies 419 between the original and diluted extracts indicates that there is a different deposition mechanism 420 operating in the two cases. In order to consider this in more detail, let us look first at aggregation 421 in bulk coffee extracts upon their heating.

422 As fouling is primarily driven by interactions between depositing entities themselves rather 423 than between depositing entities and the original surface, it is instructive to consider a possible 424 relationship between surface deposition and aggregation in the bulk suspension. Here we used 425 static light scattering to investigate the Brownian aggregation of colloidal particles in the bulk 426 extracts at various dilutions and temperatures. In Figure 8a we show the measured scattered light 427 intensity for the 200 times diluted extract after heating for 1 hour at the indicated temperatures. 428 The pattern corresponds to gradual aggregation of smaller particles to larger clusters. There is a 429 strong increase in the mean radius of gyration with increasing temperature, as can be seen in 430 Figure 9. The observed behavior is very similar to the one found in Figure 6 for the rate of 431 deposition.

432 This is further supported by the fact that the activation energy for deposition from diluted 433 extracts observed in Figure 7 is of the same order of magnitude as for the so-called reaction 
434 limited aggregation, where a typical energy barrier for aggregation is on the order of 10kT 435 (Hunter, 2001), corresponding to the activation energy of $25 \mathrm{~kJ} / \mathrm{mol}$. These results indicate a 436 correlation between irreversible aggregation in solution at elevated temperatures and secondary 437 surface deposition in diluted coffee extracts.

438 A scattered intensity pattern very different from the one observed in diluted extracts was found 439 when the original extract was heated at higher temperatures, as shown in Figure 8b. It appears 440 that large particles of the order of tens of microns emerge after heating at elevated temperatures, 441 although a good portion of the original colloidal particles is still present in the system. This 442 indicates that in the original extract there is an irreversible formation of large aggregates upon 443 heating, indicative of an association or a phase transition, as opposed to the gradual cluster444 cluster aggregative growth seen in diluted extracts. These larger aggregates can then either 445 directly assemble at the surface, or be deposited from the solution, in either case leading to much 446 higher deposition rates compared to diluted extracts. These results suggest that the aggregation 447 and deposition mechanisms in coffee extracts are strongly dependent on their concentration. It is 448 worth noting that concentration driven association phenomena have been observed using light 449 scattering in moderately concentrated solutions of peptides (Javid et al., 2011), proteins (Le Bon 450 et al., 1999) and polysaccharides (Burchard, 2001), as well as in coffee extracts using 451 viscosimetry (Redgwell et al., 2005).

\section{Microscopy and gravimetric study}

453 Scanning electron microscopy images of surfaces before and after deposition were taken in 454 order to complement the information obtained by OWLS. Images of bare silica surface are flat 455 and featureless down to resolution length scales of tens of nanometers, as shown in Figure S1a. 456 The primary layers detected by OWLS are not visible by SEM and the corresponding image 457 looks like those of the bare surface, even when a scratch to the primary layer is done. Missing 458 contrast between the original surface and the deposited layer indicates information that the 459 primary layer is uniform and homogeneous at the used resolution.

460 The secondary deposited layer on silica surface exposed to the extract at $50^{\circ} \mathrm{C}$ for 5 minutes 461 can be made visible through SEM by scratching it to enhance the contrast between the layer and 462 the surface (Figure S1b). The mass of the secondary deposit measured by OWLS for these 463 conditions was about $1 \mathrm{mg} \cdot \mathrm{m}^{-2}$ which was on the top of the primary layer constituted 464 approximately by another $1 \mathrm{mg} \cdot \mathrm{m}^{-2}$. The contrast between surface and deposited layer was 465 stronger in the case where the surface was exposed to the extract at $70^{\circ} \mathrm{C}$ for five minutes, as 
shown in Figure S1c. In this case the mass measured by OWLS during the secondary deposition indicates that in all cases the deposited layers were homogeneous and uniformly covering the exposed surfaces.

470 We further used gravimetry in order to measure the deposition rates at longer deposition times, and therefore for thicker deposited layers. As mentioned above, the gravimetry measurements can be performed only after an appreciable amount of mass has been deposited, which imposes a lower limit to the applicability of this method, which happens to be very close to the upper limit of OWLS. Therefore with this technique one can compare the deposition rates and deposited mass over longer time for dense, concentrated extracts and follow the history of the deposition process beyond the limits of OWLS. This also gives us the opportunity to verify the compatibility between these two techniques.

478 One important aspect in the design of these experiments is that in the measurement cells used for gravimetry and OWLS the hydrodynamic conditions at the deposition surface should be similar. As described in the experimental section this is obtained by a proper design of the gravimetric cell which in the experiments discussed in the following led to a velocity gradient at the surface equal to about $500 \mathrm{~s}^{-1}$. Measurements were performed for the coffee extract at $65^{\circ} \mathrm{C}$. The results in Figure 10 show that the deposited mass as a function of time increases in a log-log plot in a consistent manner going from the short time OWLS measurements (diamonds) to the long-time gravimetric measurements (squares). This results in comparable deposition rates equal to about $1 \mathrm{mg} \cdot \mathrm{m}^{-2} \cdot \mathrm{min}^{-1}$, as determined by the two methods.

487 Gravimetric experiments have been performed using the original extract to measure the deposition rates at higher temperatures, i.e. 73 and $83^{\circ} \mathrm{C}$. The obtained values are very similar to the one measured at $65^{\circ} \mathrm{C}$, thus confirming the plateau in the deposition rate shown in Figure 6

\section{Conclusions}

The deposition kinetics of an industrial coffee extract at wide range of temperatures was studied by OWLS and gravimetry. The first step in deposition formed a primary layer of about 1 $\mathrm{mg} . \mathrm{m}^{-2}$ on all the considered surfaces. At ambient temperature the secondary exposure of the primarily covered surface leads to reversible deposition, attributed to the electrolyte adsorption. 
498 Temperature and concentration were found to be the main operating parameter driving 499 deposition, which in the original extract reached a maximum rate at $65^{\circ} \mathrm{C}$. Gravimetry was used 500 as an independent method to measure the deposition rates. A comparison of the deposition rates, measured by gravimetry at longer times and by OWLS at shorter times, shows a very good consistency between the two methods. Deposition rates at ambient temperature were only little dependent on extract concentration, although they increase moderately with decreasing extract $\mathrm{pH}$ between 6.5 and 4. Activation energies for deposition kinetics were determined for both the original and diluted extracts. The activation energy for the original extract (solid concentration $13.3 \mathrm{wt} \%$ ) was found to be about $130 \mathrm{~kJ} / \mathrm{mol}$ between 25 and $65^{\circ} \mathrm{C}$. However, the activation energy for diluted extracts was only about $30 \mathrm{~kJ} / \mathrm{mol}$. This can be due to the fact that the surface in contact with the diluted extracts is saturated with a loosely bound layer of material, which gradually becomes incorporated into irreversibly bound deposits. Therefore the buildup of the irreversibly bound deposit is independent of the extract concentration, provided that it is sufficient to reversibly saturate the available surface. In contrast, the original concentrated extract exhibits an irreversible association of suspended entities to large clusters at elevated temperatures, as indicated by static light scattering, leading to a different deposition mechanism with much higher deposition rates at higher temperatures. Our findings contribute to better understanding of mechanism and kinetics of deposition from protein/polysaccharide aqueous systems, which is a major cause of fouling at heat exchange surfaces of evaporators in production of instant coffee powders and other similar operations. In particular, the knowledge of deposition kinetics and corresponding activation energies will allow to determine time evolution of deposit thickness on evaporator walls and to assess its effect on heat transfer coefficients as a function of operating time and temperature. This will help to guide better design and improved operation of relevant processes in food and chemical processing industries.

\section{Acknowledgements}

This work was supported by Nestlé and by the Swiss Commission for Technological Innovation (KTI, Grant No. 5976.1). We would like to thank Dr. Remy Liardon and his discussions. 
532 Anema, S. G. (2000). Effect of milk concentration on the irreversible thermal denaturation and 533 disulfide aggregation of beta-lactoglobulin. Journal of Agricultural and Food Chemistry, 48, 534 4168-4175. DOI: 10.1021/jf991173e

535 Burchard, W. (2001). Structure formation by polysaccharides in concentrated solution. 536 Biomacromolecules, 2, 342-353. DOI: 10.1021/bm0001291

537 Changani, S. D., BelmarBeiny, M. T. \& Fryer, P. J. (1997). Engineering and chemical factors 538 associated with fouling and cleaning in milk processing. Experimental Thermal and Fluid 539 Science, 14, 392-406. DOI: 10.1016/S0894-1777(96)00141-0

540 Defeijter, J. A., Benjamins, J. \& Veer, F. A. (1978). Ellipsometry as a Tool to Study Adsorption 541 Behavior of Synthetic and Biopolymers at Air-Water-Interface. Biopolymers, 17, 1759-1772. $542 \quad$ DOI: 10.1002/bip.1978.360170711

543 Extrand, C. W. (1994). Spin-Coating of Very Thin Polymer-Films. Polymer Engineering and 544 Science, 34, 390-394. DOI: 10.1002/pen.760340503

545 Grancic, P., Illeova, V., Polakovic, M., Sefcik, J. (2012). Thermally induced inactivation and 546 aggregation of urease: experiments and population balance modelling. Chemical Engineering 547 Science, 70, 14-21. DOI: 10.1016/j.ces.2011.07.050

548 Griesser, H. J., Hartley, P. G., McArthur, S. L., McLean, K. M., Meagher, L. \& Thissen, H. 549 (2002). Interfacial properties and protein resistance of nano-scale polysaccharide coatings. Smart 550 Materials \& Structures, 11, 652-661. DOI:10.1088/0964-1726/11/5/305

551 Haarmans, M. T. \& Bedeaux, D. (1995). Optical Properties of Thin Films up to Second Order in 552 the Thickness. Thin Solid Films, 258, 213-223. DOI: 10.1016/0040-6090(94)06395-8

553 Höök, F., Vörös, J., Rodahl, M., Kurrat, R., Böni, P., Ramsden, J. J., Textor, M., Spencer, N. D., 554 Tengvall, P., Gold, J. \& Kasemo, B. (2002). A comparative study of protein adsorption on 555 titanium oxide surfaces using in situ ellipsometry, optical waveguide lightmode spectroscopy, and 556 quartz crystal microbalance/dissipation. Colloids and Surfaces B: Biointerfaces, 24, 155-170 557 DOI:10.1016/S0927-7765(01)00236-3

558 Huang, N.-P. (2002). Biochemical Interactions of Surface-Bound PEG Copolymers. PhD Thesis, 559 ETH, Zurich.

560 Hunter, R. J. (2001). Foundations of Colloid Science. Oxford University Press. 
561 Javid, N., Vogtt, K., Roy, S., Hirst, A. R., Hoell, A., Hamley, I. W., Ulijn, R. V., Sefcik, J. 562 (2011). Supramolecular structures of enzyme clusters. Journal of Physical Chemistry Letters, 2, 563 1395-1399. DOI: 10.1021/jz200446j

564 Jong, P. (1997). Impact and Control of Fouling in Milk Processing. Trends in Food Science \& 565 Technology, 8, 401-405. DOI: 10.1016/S0924-2244(97)01089-3

566 Kosmulski, M. (2001). Chemical properties of Material Surfaces. Dekker.

567 Kroslak, M., Sefcik, J. \& Morbidelli, M. (2007). Effects of Temperature, pH and Salt

568 Concentration on $\beta$-Lactoglobulin Deposition Kinetics Studied by Optical Waveguide Lightmode

569 Spectroscopy. Biomacromolecules, 8, 963-970. DOI: 10.1021/bm060293+

570 Lavalle, P., Picart, C., Mutterer, J., Gergely, C., Reiss, H., Voegel, J. C., Senger, B. \& Schaaf, P.

571 (2004). Modeling the buildup of polyelectrolyte multilayer films having exponential growth.

572 Journal of Physical Chemistry B, 108, 635-648. DOI: 10.1021/jp035740j

573 Le Bon, C., Nicolai, T. \& Durand, D. (1999). Growth and structure of aggregates of heat-

574 denatured $\beta$-Lactoglobulin. International Journal of Food Science and Technology, 34, 451-465.

575 DOI: $10.1046 /$ j.1365-2621.1999.00310.x

576 Mann, E. K. (2001). Evaluating optical techniques for determining film structure: Optical 577 invariants for anisotropic dielectric thin films. Langmuir, 17, 5872-5881. DOI: $578 \quad 10.1021 / \mathrm{la001746d}$

579 Nakanishi, K., Sakiyama, T. \& Imamura, K. (2001). On the adsorption of proteins on solid 580 surfaces, a common but very complicated phenomenon. Journal of Bioscience and 581 Bioengineering, 91, 233-244. DOI: 10.1016/S1389-1723(01)80127-4

582 Nellen, M. (1992). Integrated Optical Input Grating Couplers as Direct Chemo and Biosensors. 583 PhD Thesis, ETH, Zurich.

584 Pasche, S., Voros, J., Griesser, H. J., Spencer, N. D. \& Textor, M. (2005). Effects of ionic 585 strength and surface charge on protein adsorption at PEGylated surfaces. Journal of Physical 586 Chemistry B, 109, 17545-17552. DOI: 10.1021/jp050431+

587 Picart, C., Ladam, G., Senger, B., Voegel, J. C., Schaaf, P.,\& Gergely, C. (2001). Determination 588 of structural parameters characterizing thin films by optical methods: A comparison between 589 scanning angle reflectometry and optical waveguide lightmode spectroscopy. Journal of 590 Chemical Physics, 115, 1086-1094. DOI: 10.1063/1.1375156 
591 Picart, C., Gergely, C., Arntz, Y., Voegel, J. C., Schaaf, P.,\& Senger, B. (2004). Measurement of

592 film thickness up to several hundreds of nanometers using optical waveguide lightmode 593 spectroscopy. Biosensors \& Bioelectronics, 20, 553-561. DOI: 10.1016/j.bios.2004.03.005

594 Redgwell, R. J., Schmitt, C., Beaulieu, M. \& Curti, D. (2005). Hydrocolloids from coffee:

595 physicochemical and functional properties of an arabinogalactan-protein fraction from green

596 beans. Food Hydrocolloids, 19, 1005-1015. DOI: 10.1016/j.foodhyd.2004.12.010

597 Relkin, P. (1996). Thermal unfolding of $\beta$-lactoglobulin, $\alpha$-lactalbumin, and bovine serum

598 albumin. A thermodynamic approach. Critical Reviews in Food Science and Nutrition, 36, 565-

599 601. DOI:10.1080/10408399609527740

600 Saini, S., Kurrat, R., Prenosil, J. E. \& Ramsden, J. J. (1994). Temperature Dependence of

601 Pyrolyzed Sol-Gel Planar Waveguide Parameters. Journal of Physics D-Applied Physics, 27, 602 1134-1138. DOI:10.1088/0022-3727/27/6/009

603 Sava, N., Van der Plancken, I., Claeys, W. \& Hendrickx, M. (2005). The kinetics of heat-induced

604 structural changes of $\beta$-lactoglobulin. Journal of Dairy Science, 88, 1646-1653. DOI: 605 10.3168/jds.S0022-0302(05)72836-8

606 Schubert, D. W. (1997). Spin coating as a method for polymer molecular weight determination.

607 Polymer Bulletin, 38, 177-184. DOI: 10.1007/s002890050035

608 Sefcik, J., Kroslak, M. \& Morbidelli, M. (2002). Optical response of porous titania-silica 609 waveguides to surface charging in electrolyte filled pores. Helvetica Chimica Acta, 85, 3508-

610 3515. DOI: 10.1002/1522-2675(200210)85:10<3508::AID-HLCA3508>3.0.CO;2-M

611 Tiefenthaler, K. \& Lukosz, W. (1989). Sensitivity of Grating Couplers as Integrated-Optical 612 Chemical Sensors. Journal of the Optical Society of America B-Optical Physics, 6, 209-220. 613 DOI: 10.1364/JOSAB.6.000209

614 Van Tassel, P. R. (2003). Statistical mechanical modeling of protein adsorption. 615 Materialwissenschaft Und Werkstofftechnik, 34, 1129-1132. DOI: 10.1002/mawe.200300703

616 Visser, J. \& Jeurnink, T. J. M. (1997). Fouling of heat exchangers in the dairy industry. 617 Experimental Thermal and Fluid Science, 14, 407-424. DOI: 10.1016/S0894-1777(96)00142-2

618 Vogtt, K., Javid, N., Alvarez, E., Sefcik, J., Bellissent-Funel, M.-C. (2011). Tracing nucleation 619 pathways in protein aggregation by using small angle scattering methods. Soft Matter, 7, 3906620 3914. DOI: 10.1039/C0SM00978D 
621 Voros, J. (2004). The density and refractive index of adsorbing protein layers. Biophysical 622 Journal, 87, 553-561. DOI: 10.1529/biophysj.103.030072

623 


\section{List of Tables}

Table 1. Refractive indices as a function of temperature. T denotes temperature in ${ }^{\circ} \mathrm{C}$ and $x_{E}$ is the weight concentration of solid content in coffee extract suspension (in g.cm ${ }^{-3}$ ), $n_{C, E}$ denotes refractive index of coffee extract and $n_{C, \mathrm{H}_{2} \mathrm{O}}$ denotes refractive index of water.

Table 2. Deposited amount of the irreversible primary layer from the coffee extract on various surfaces at ambient temperature.

Table 3. Influence of $\mathrm{pH}$ on secondary deposition rates of concentrated coffee extract. 
Table 1. Refractive indices as a function of temperature. $\mathrm{T}$ denotes temperature in ${ }^{\circ} \mathrm{C}$ and $x_{E}$ is the weight concentration of solid content in coffee extract suspension (in $\mathrm{g} . \mathrm{cm}^{-3}$ ), $n_{C, E}$ denotes refractive index of coffee extract and $n_{C, H_{2} O}$ denotes refractive index of water.

\begin{tabular}{|l|l|l|l|}
\hline Parameter & $25^{\circ} \mathrm{C}$ & $\mathrm{T}\left[{ }^{\circ} \mathrm{C}\right]$ & Source \\
\hline$n_{C, H_{2} O}$ & 1.331144 & $\begin{array}{l}n_{C, H_{2} O}^{25^{\circ} C}-\frac{75453.41 \Delta T+2340.431 \Delta T^{2}+6.363191 \Delta T^{3}}{T .10^{7}+65.7081 .10^{7}} ; \\
\text { where } \Delta T=T-25\end{array}$ & \\
\hline$n_{C, E}$ & $0.2090 x_{E}+n_{C, H_{2} O}^{25^{o} C}$ & $\left(4.2725 .10^{-6} T^{2}-4.665 .10^{-4} T+2.1795 .10^{-1}\right) x_{E}+n_{C, H_{2} O}^{T} O$ & $\begin{array}{l}\text { measured by } \\
\text { refractometer }\end{array}$ \\
\hline$n_{S}$ & 1.525718 & $1.52542-1.23 .10^{-6} T$ & $a$ \\
\hline \multicolumn{2}{|l|}{$a-$ reference (Saini et al., 1994) } \\
\hline
\end{tabular}


Table 2. Deposited amount of the irreversible primary layer from the coffee extract on various surfaces at ambient temperature.

\begin{tabular}{|l|l|l|}
\hline Surface & $\begin{array}{l}\text { Extract Solid Content } \\
{[\mathrm{wt} \%]}\end{array}$ & $\begin{array}{l}\text { Deposited Mass } \\
{\left[\mathrm{mg} \cdot \mathrm{m}^{-2}\right]}\end{array}$ \\
\hline Silica & 13.3 & 1.2 \\
\hline Silica & 1.33 & 1.1 \\
\hline Silica & 0.034 & 1.1 \\
\hline Niobia & 13.3 & 1.2 \\
\hline Alumina & 13.3 & 0.7 \\
\hline PEG-3.5-PLL & 13.3 & 0.4 \\
\hline Polystyrene & 13.3 & 0.90 \\
\hline
\end{tabular}


Table 3. Influence of $\mathrm{pH}$ on secondary deposition rates of concentrated coffee extract.

\begin{tabular}{|l|l|l|}
\hline $\begin{array}{l}\text { Temperature } \\
{\left[{ }^{\circ} \mathrm{C}\right]}\end{array}$ & $\mathrm{pH}$ & $\begin{array}{l}\text { Deposition Rate } \\
{\left[\mathrm{mg} \cdot \mathrm{m}^{-2} \cdot \mathrm{min}^{-1}\right]}\end{array}$ \\
\hline \multirow{3}{*}{25} & 4 & 0.006 \\
\cline { 2 - 4 } & 5 & 0.003 \\
\cline { 2 - 4 } & 6.5 & 0.003 \\
\hline \multirow{3}{*}{65} & 4 & 1.6 \\
\cline { 2 - 4 } & 5 & 1.2 \\
\cline { 2 - 4 } & 6.5 & 0.3 \\
\hline
\end{tabular}




\section{List of Figures}

Figure 1. Primary exposure of silica and polystyrene surfaces to the original extract (13.3 wt $\%), \mathrm{pH}$ 5.5 at $25^{\circ} \mathrm{C}$.

Figure 2. Three subsequent exposures of silica surface to the original extract at ambient temperature

Figure 3. a) Waveguide thickness as a function of temperature. b) Waveguide refractive index as a function of temperature.

Figure 4. a) Cell temperature for secondary deposition experiment at $60^{\circ} \mathrm{C}$. b) Deposited mass for secondary deposition experiment at $60^{\circ} \mathrm{C}$

Figure 5. Comparison between deposition rates determined online and off-line for diluted extract (1.3 $\mathrm{wt} \%$ ) as a function of temperature

Figure 6. Deposition rates for the original extract as a function of temperature

Figure 7. Arrhenius plot for the deposition rates

Figure 8. a) Scattered light intensity measured by SLS in 200 times diluted extract after aggregation at the indicated temperatures. b) Scattered light intensity measured by SLS in the original extract after aggregation at the indicated temperatures.

Figure 9. Radius of gyration measured by SLS for the 200 times diluted extract as a function of the aggregation temperatures.

Figure 10. Deposited mass as a function of time at $65^{\circ} \mathrm{C}$ for the original extract. Diamonds: OWLS; squares: gravimetry. 


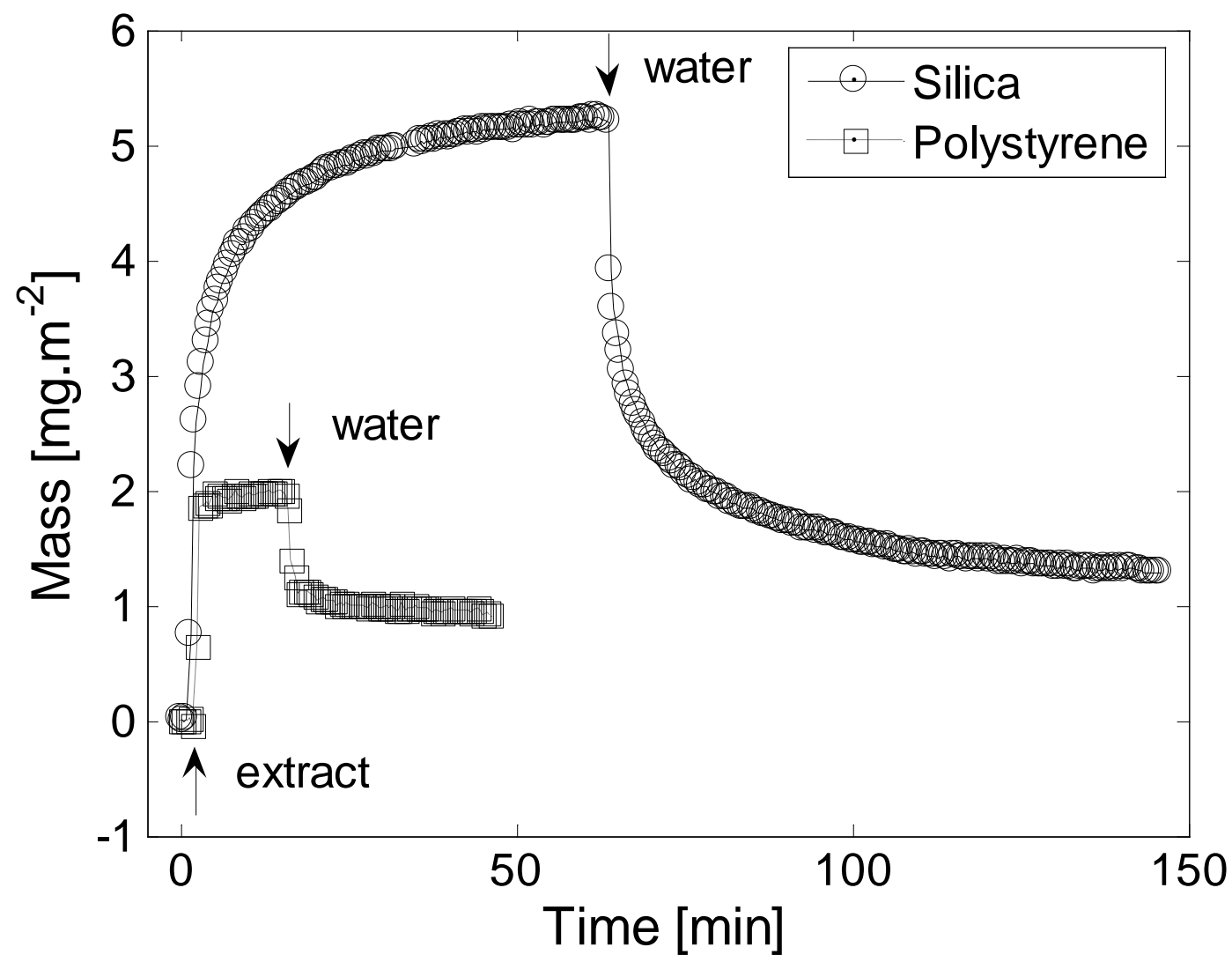

Figure 1. Primary exposure of silica and polystyrene surfaces to the original extract (13.3 wt $\%)$, $\mathrm{pH} 5.5$ at $25^{\circ} \mathrm{C}$. 


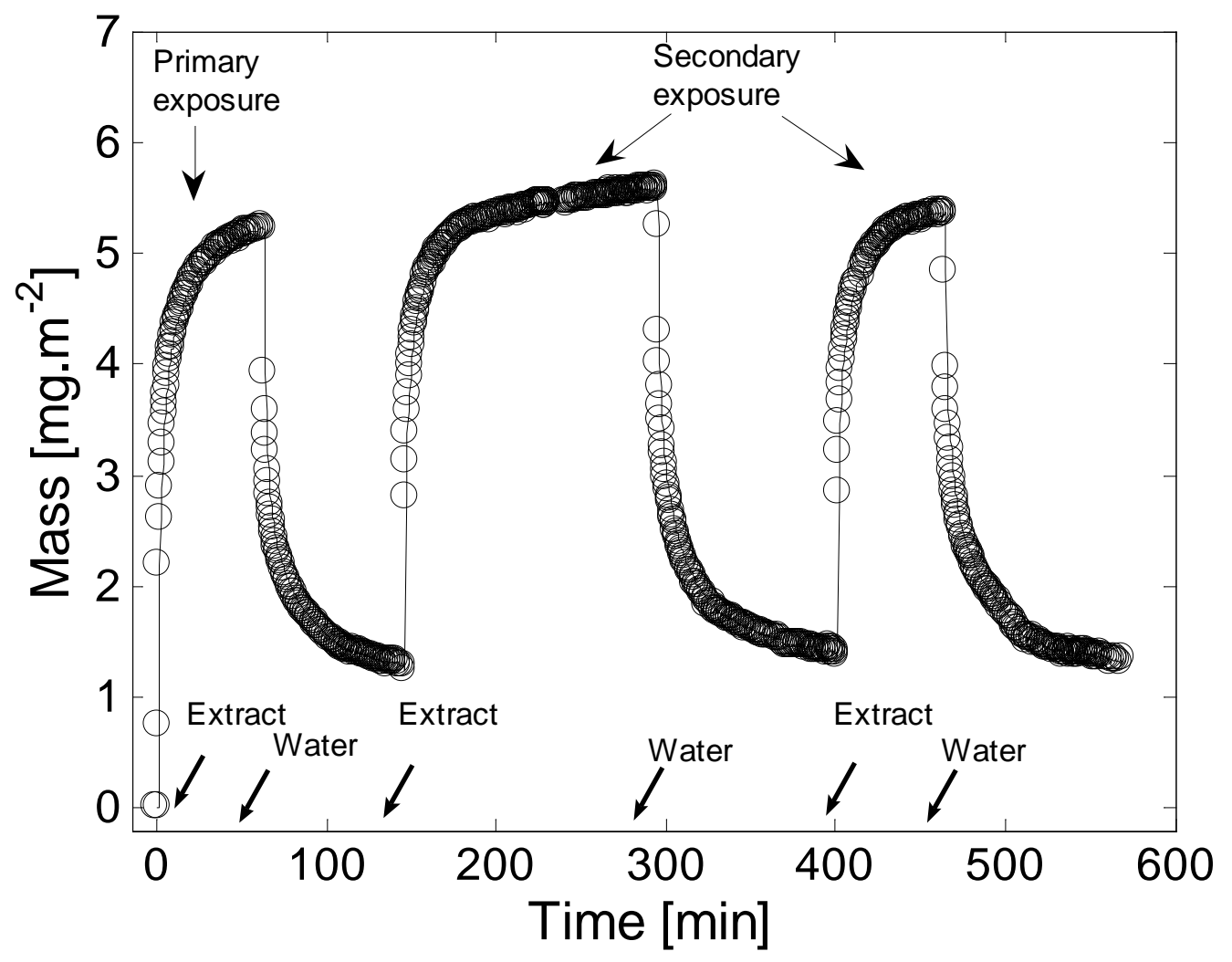

Figure 2. Three subsequent exposures of silica surface to the original extract at ambient temperature. 

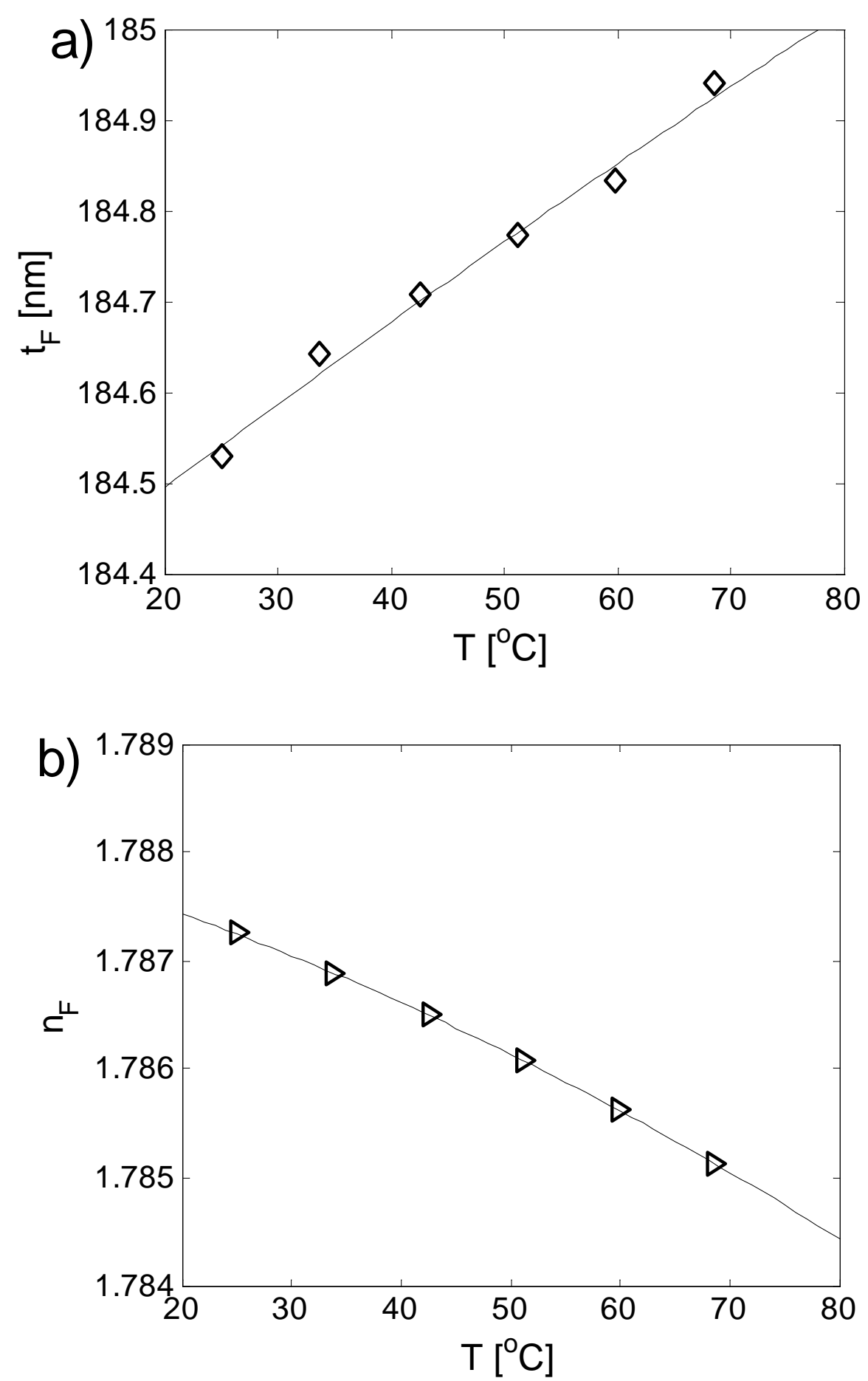

Figure 3. a) Waveguide thickness as a function of temperature. b) Waveguide refractive index as a function of temperature. 

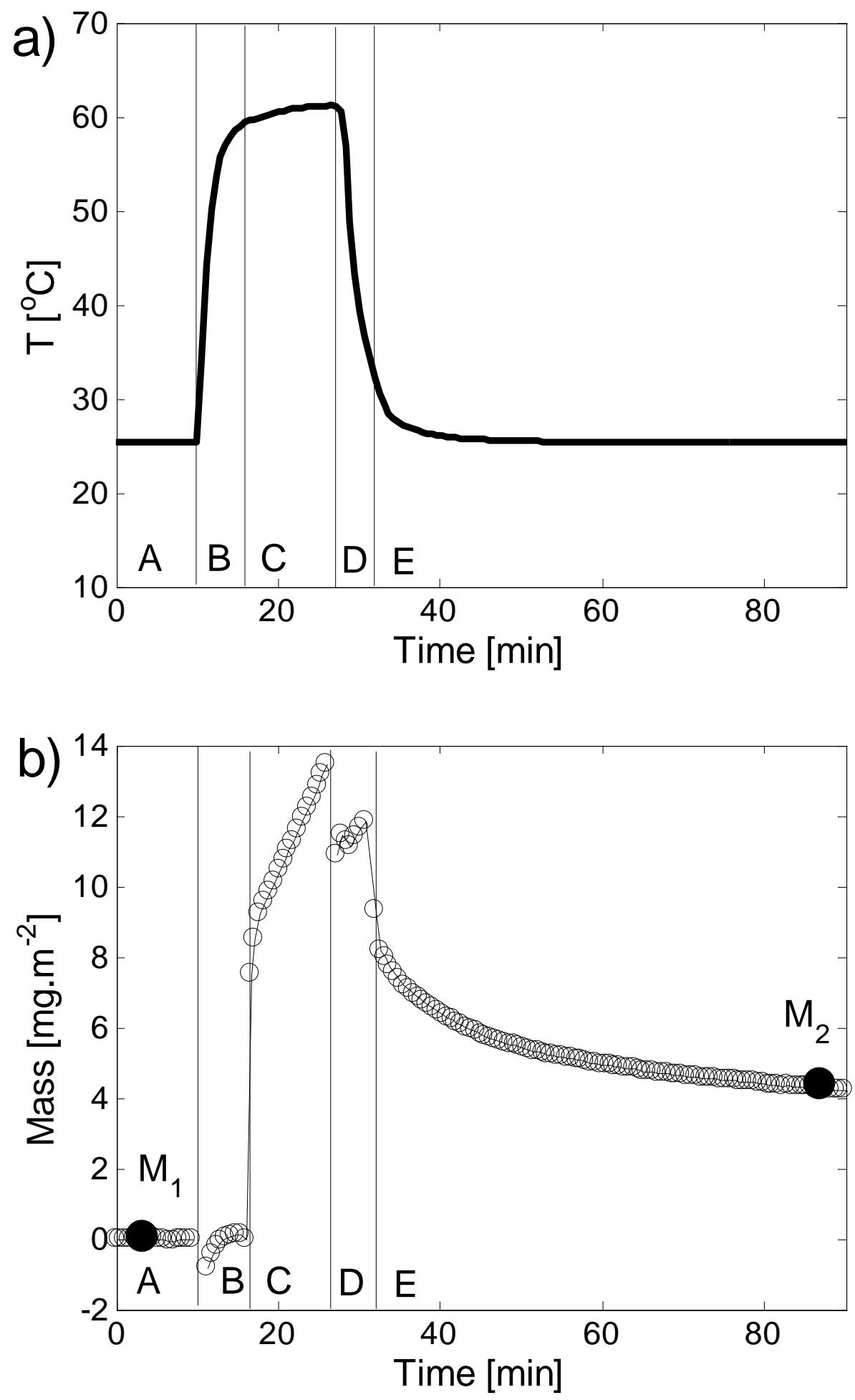

Figure 4. a) Cell temperature for secondary deposition experiment at $60^{\circ} \mathrm{C}$. b) Deposited mass for secondary deposition experiment at $60^{\circ} \mathrm{C}$. 


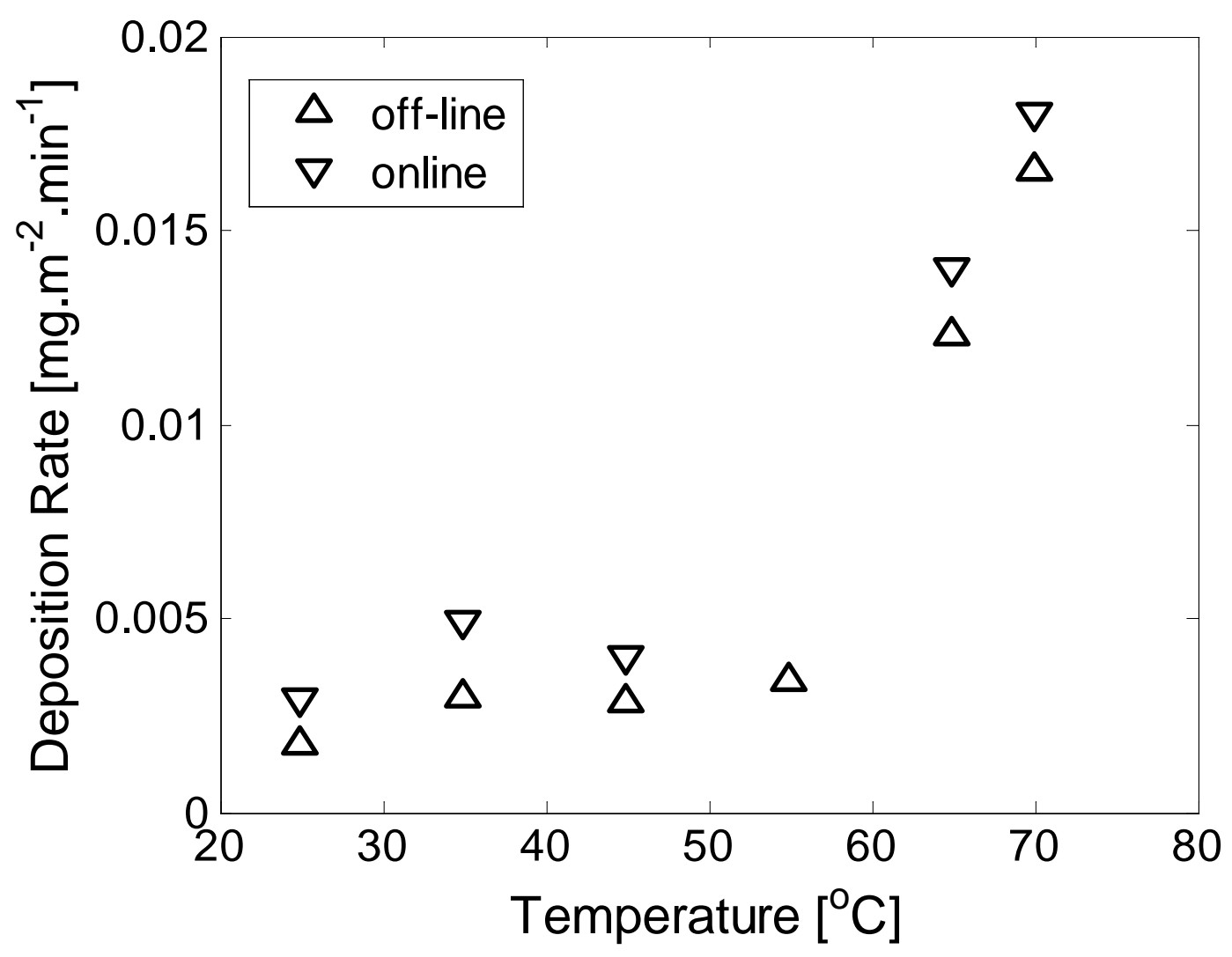

Figure 5. Comparison between deposition rates determined online and off-line for diluted extract $(1.3 \mathrm{wt} \%)$ as a function of temperature. 


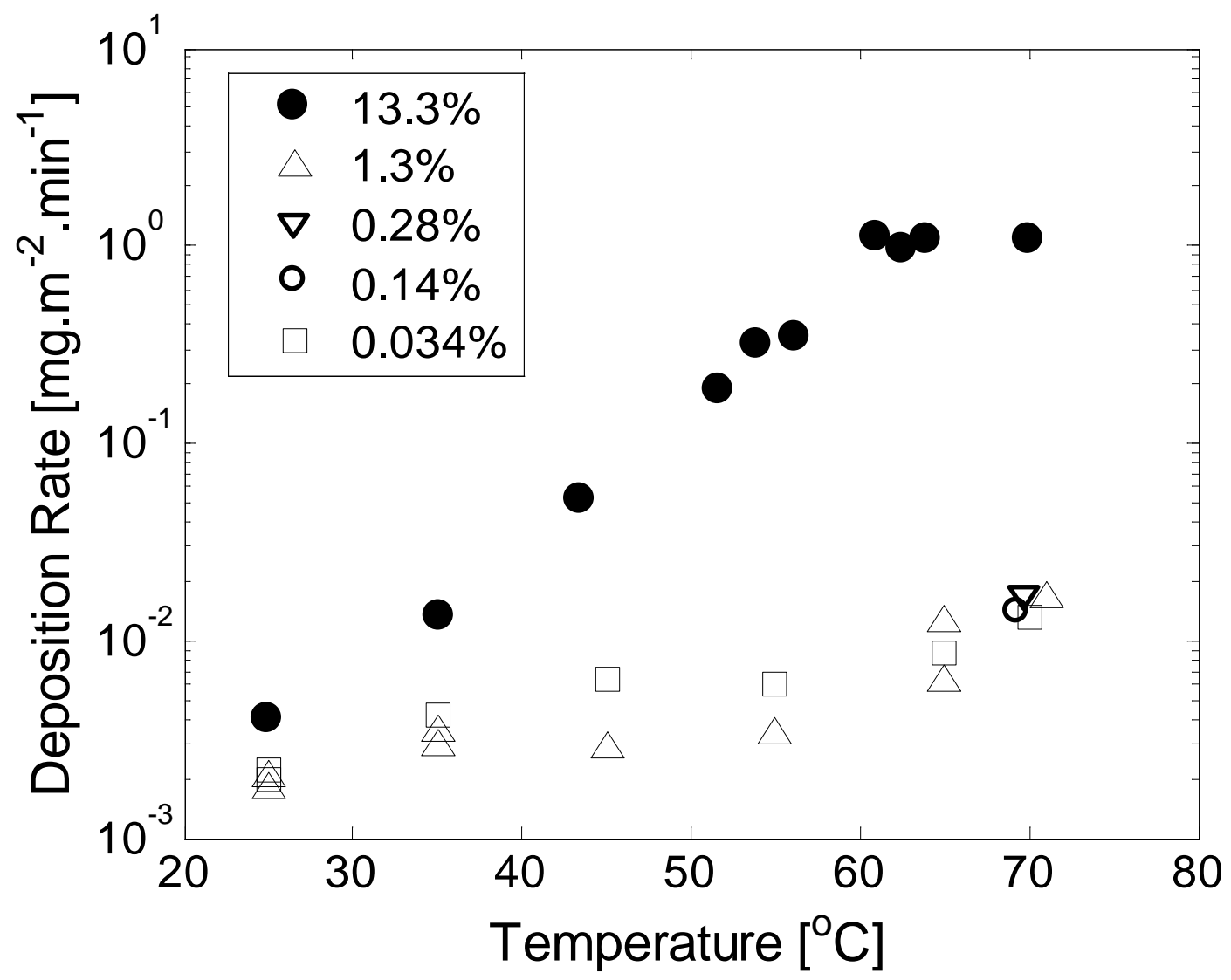

Figure 6. Deposition rates for the original extract as a function of temperature. 


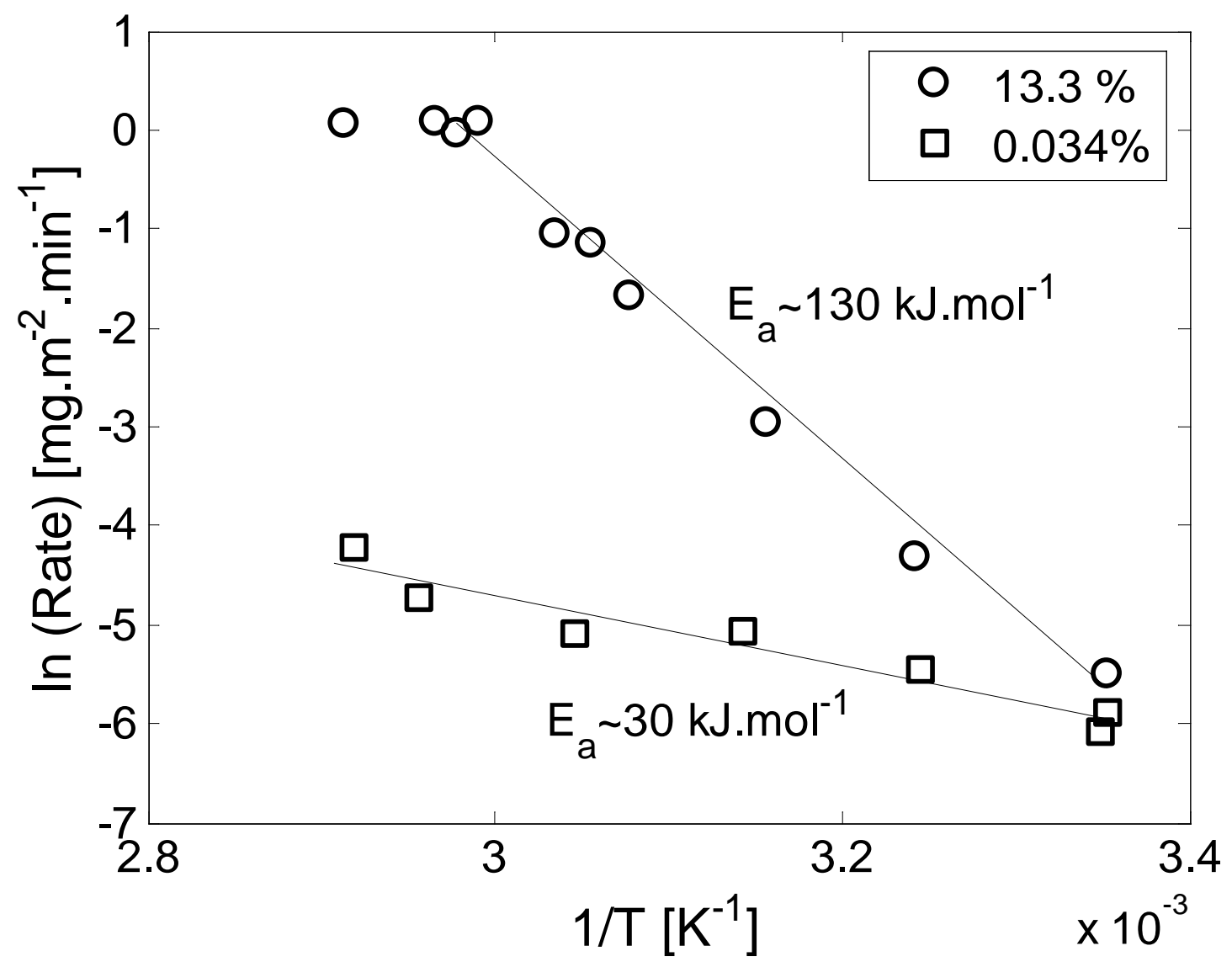

Figure 7. Arrhenius plot for the deposition rates. 

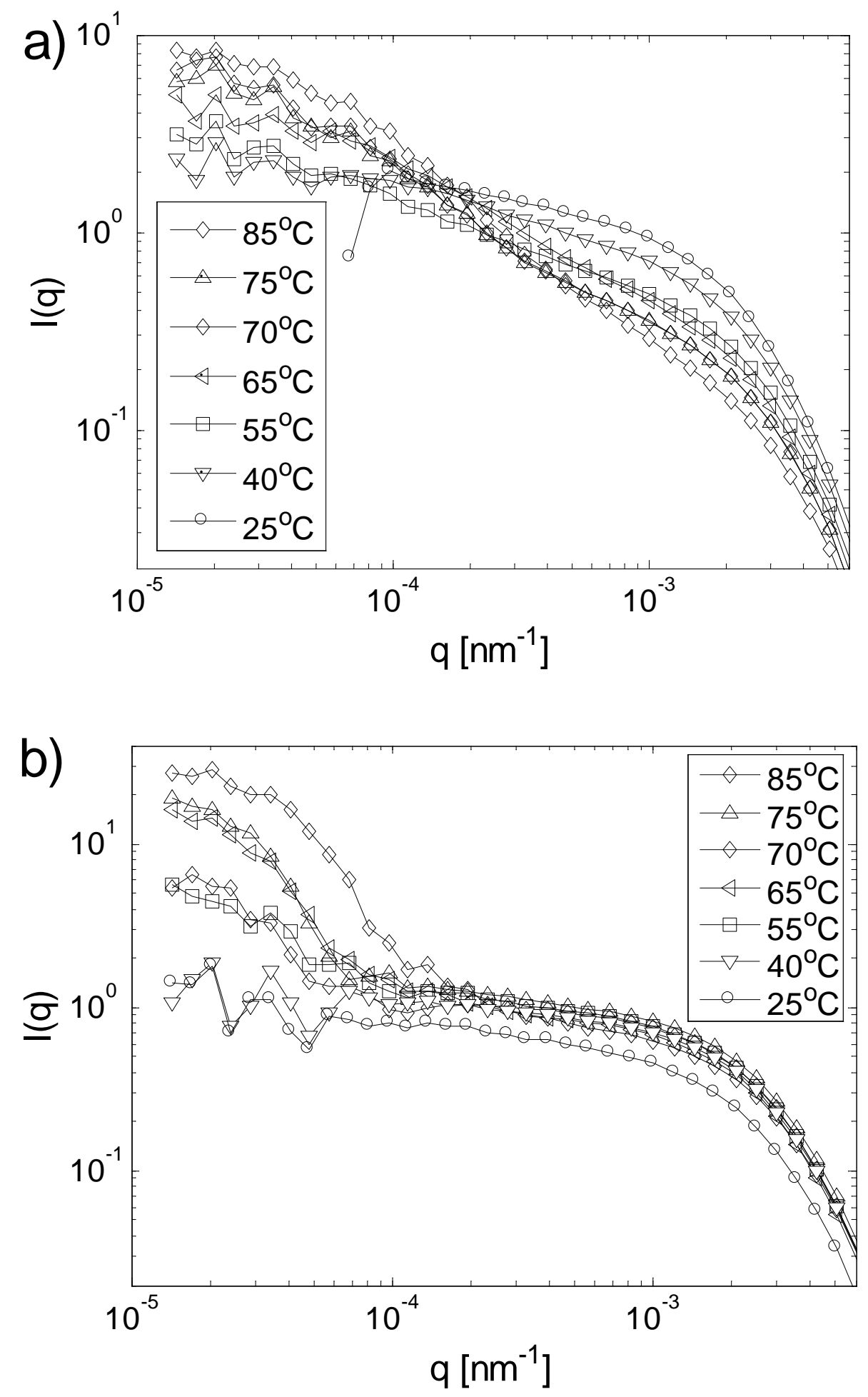

Figure 8. a) Scattered light intensity measured by SLS in 200 times diluted extract after aggregation at the indicated temperatures. b) Scattered light intensity measured by SLS in the original extract after aggregation at the indicated temperatures. 


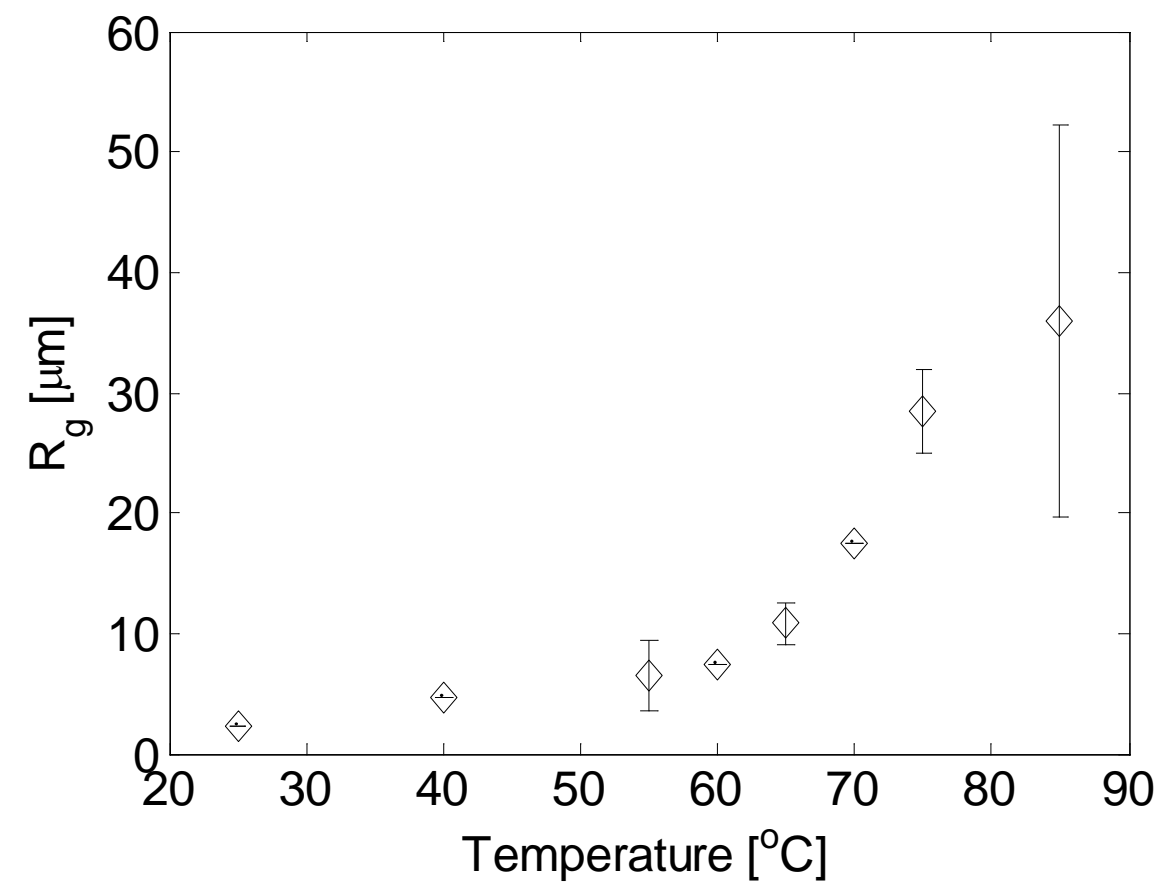

Figure 9. Radius of gyration measured by SLS for the 200 times diluted extract as a function of the aggregation temperatures. Error bars represent confidence intervals for radii of gyration estimated from data in Figure 8a. 


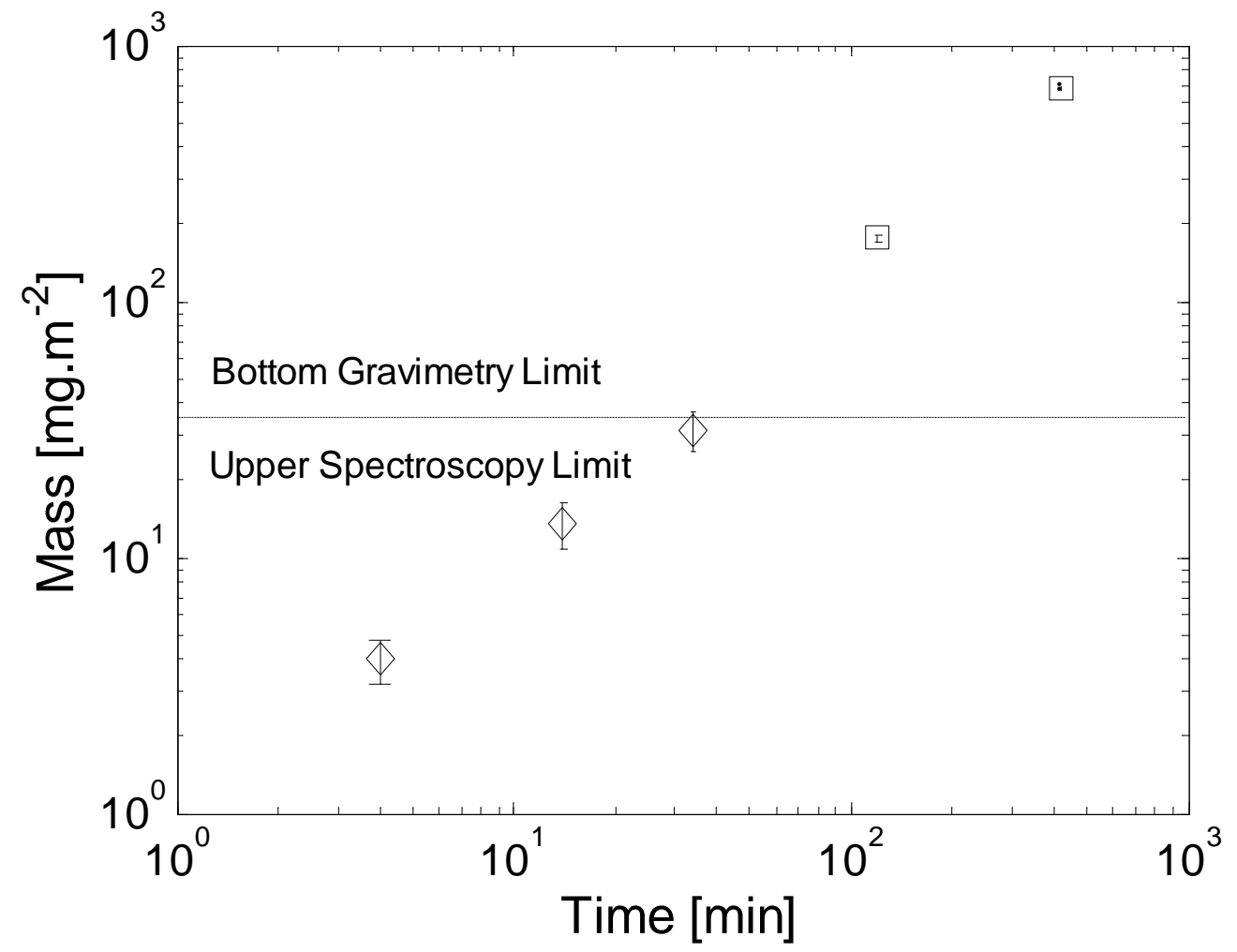

Figure 10. Deposited mass as a function of time at $65^{\circ} \mathrm{C}$ for the original extract. Diamonds: OWLS; squares: gravimetry. 
